Jurnal Ekonomi dan Bisnis, Volume 14 Nomor 2, November, 91-104

\title{
PENGEMBANGAN KOMPETENSI SUMBER DAYA MANUSIA DI LEMBAGA KEUANGAN
}

\author{
Ferdianta Baskara, Tika Magdalena Sitepu, M. Fajri
}

\begin{abstract}
ABSTRAK
Perusahaan perlu menerapkan sistem manajemen SDM berbasis kompetensi untuk mengembangkan potensi karyawan sehingga mencapai prestasi dan kinerja perusahaan seperti yang diinginkan. Sumber Daya Manusia di perusahaan mempunyai arti yang sama pentingnya dengan pekerjaan itu sendiri, mengingat pentingnya peran sumber daya manusia di perusahaan, sumber daya manusia sebagai faktor penentu organisasi, maka kompetensi menjadi aspek yang menentukan keberhasilan perusahaan. Dengan kompetensi yang tinggi yang dimiliki oleh sumber daya manusia akan menentukan kualitas SDM yang dimiliki yang pada akhirnya akan menentukan kualitas kompetitif perusahaan itu sendiri. Penelitian ini bertujuan untuk menguji keberadaan kompetensi dari sumber daya manusia di lembaga keuangan terhadap kinerja lembaga keuangan. Populasi penelitian adalah semua karyawan yang berhubungan langsung dengan aktivitas keuangan di lembaga keuangan di kota Malang. Sampel ditentukan dengan teknik purpose sampling, dengan responden seluruh karyawan di bidang keuangan sebanyak 100 orang. Metode pengumpulan data yang digunakan dengan teknik kuisioner dan wawancara. Teknik analisis menggunakan analisis regresi linier berganda. Faktor-Faktor seperti pendidikan, kemampuan kerja, pelatihan, integritas terbukti memiliki pengaruh yang signifikan terhadap kinerja. Sedangkan budaya organisasi, kepemimpinan dan lingkungan kerja tidak terbukti memiliki pengaruh. Nilai koefisien determinasi sebesar $48.5 \%$ sedangkan sisanya dipengaruhi oleh faktor lain diluar variable penelitian.
\end{abstract}

Kata-kata kunci : kinerja organisasi, kinerja karyawan, kompetensi

\begin{abstract}
Companies need to implement a competency-based HR management system to develop employee potential so that they can achieve the desired achievements and company performance. Human Resources in the company have the same importance as the work itself, given the important role of human resources in the company, human resources as a determining factor for the organization, competence is an aspect that determines the success of the company. With high competence possessed by human resources will determine the quality of their human resources which will ultimately determine the competitive quality of the company itself. This study aims to examine the existence of competence of human resources in financial institutions on the performance of financial institutions. The research population is all employees who are directly related to financial activities in financial institutions in Malang. The sample is determined by purposive sampling technique, with respondents of all employees in the financial sector as many as 100 people. The data collection methods used were questionnaire and interview techniques. The analysis technique uses multiple linear regression analysis. Factors such as education, employability, training, integrity are proven to have a significant effect on performance. Meanwhile, organizational culture, leadership and work environment are not proven to have an influence. The coefficient of determination is $48.5 \%$, while the rest is influenced by other factors outside the research variables.
\end{abstract} Key words: organizational performance, employee performance, competence 
Perlu adanya pelatihan - pelatihan yang bertujuan untuk meningkatkan kompetensi masingmasing karyawan termasuk di sisi administrasi, pelayanan dan pengembangan diri supaya dalam hal ini kompetensi dari karyawan itu sendiri dapat ditingkatkan lewat pelatihan tersebut. Selain itu diharapkan di penelitian selanjutnya perlu dilibatkan variabel-variabel lain yang tidak disertakan di penelitian ini agar perkembangan topik di penelitian ini dapat dikembangkan lebih luas lagi.

\section{DAFTAR PUSTAKA}

Al Hakim, Y. R. 2014. Pengaruh Komitmen Kerja terhadap Kepuasan Kerja Guru, Jurnal Ilmiah Manajemen Pendidikan Indonesia, Vol.1 No.1 September, 15-24

Abbas, Qaisar \& Sara, Yaqoob. 2009. Effect Leadership Development on Employee Performance in Pakistan. Pakistan Economic and Social Review. Volume 47, No. 2 (Winter 2009), pp.269292.

Andayani, D., Didit D. 2010. Teori Keputusan Manajerial, Metromedia, Surabaya

Andayani, Dewi., Sherly Kabalmay, Revo Resandi, D. Darmawan. 2010. Pemberdayaan Karyawan Berbasis Keunggulan Bersaing, IntiPresindo Pustaka, Bandung

Arifin, Samsul. R. Mardikaningsih \& Yusuf R. H. 2017. Pengaruh Kedisiplinan, Kompetensi, dan Motivasi Kerja terhadap Kinerja Karyawan, Management \& Accounting Research Journal, Vol.2 No.1 November, 43-50

Armstrong, M. 1994. Manajemen Sumber Daya Manusia, Media Kompetindo, Jakarta.

Bain, David. 1982. The Productivity Prescription the Manager's guide to Improving Productivity and Profits. McGraw-Hill Book Company. Newyork

Byars, Lloyd L. \& Leslie W. Rue. 2000. Human Resource Management. Boston: McGraw-Hill.

Bohlander, George., \& Snell, Scott. 2010. Principles of Human Resource. Management, 15th ed. Mason, OH: South Western - Cengage Learning

Darmaji, Supeno. 2012. Manajemen Sumber Daya Manusia, Cendekia Press, Malang

Daft, Richard L. 2011. Era Baru Manajemen, Edisi 9 Buku 2. Jakarta: Salemba Empat.

Dale, Timpe. 2002. Seri Manajemen Sumber Daya Manusia Kinerja, cetakan kelima, Jakarta: PT Elex Media Komputindo

Darmawan, Didit. 2003. Determinan Optimalisasi Kinerja Karyawan, Jurnal Ilmu Manajemen, Vol 4 No 1, 12-24

Darmawan, Didit. 2003. Teori Pengambilan Keputusan. Universitas Atmajaya, Yogyakarta

Darmawan, Didit. 2007. Budaya Organisasi dan Pengaruhnya terhadap Kebebasan Pengambilan Keputusan Manajerial, Jurnal Media Komunikasi Ekonomi dan Manajemen, Vol.5 No.2 Januari, 40-53

Darmawan, Didit. 2011. Pengaruh Karakteristik Individu, Kompensasi dan Modal Sosial terhadap Loyalitas Kerja, Jurnal Ilmu Sosial, Vol. 5, No. 3, 135-146

Darmawan, Didit. 2010. Pengaruh Kompetensi Kerja, Budaya Organisasi, Kepemimpinan dan Kompensasi terhadap Loyalitas Kerja, Jurnal Ilmu Sosial, Vol. 4, No. 2, 63-76

Darmawan, Didit. 2017. Pemberdayaan Kerjasama, Metromedia, Surabaya

David, F.R. 1995. Strategic Management, 9 th Edition, Prentice Hall Inc, New Jersey. 
Jurnal Ekonomi dan Bisnis, Volume 14 Nomor 2, November, 91-104

Davis, Keith \& Newstrom, 2001. Perilaku Dalam Organisasi. Edisi Ketujuh. Penerbit Erlangga; Jakarta

Dirhamana, Ajisaka. 2013. Perilaku Organisasi, Jaya Ilmu Book, Semarang

Dessler, Gary. 2011. Human Resource Management: Global Edition. Pearson Higher Education

Gibson, Ivancevich \& Donelly. 2003. Organisasi. Edisi Kedelapan, Jilid 2. Binarupa Aksara; Jakarta

Gomes, Faustino Cardoso. 2005. Manajemen Sumber Daya Manusia. Penerbit Andi Yogyakarta

Gunawan, Aditya. 2015. Perilaku Organisasi. Gramedia, Jakarta

Hariani, M. 2017. Analisis Respon Pekerja terhadap Pemberdayaan Sumber Daya Manusia di Bagian Pengendalian Kualitas dalam Kegiatan Ekspor Hasil Produksi Rotan, Jurnal Agrimas, Vol.1 No.1 Juni, 19-28

Hutomo, Sanjaya.; Darmawan, Didit. 2011. Optimalisasi Manajemen Sumber Daya Manusia Menuju Keunggulan Bersaing, Jurnal Ilmu Sosial, Vol. 5, No. 1, 13-22

Irfan, Mochamad. \& H R Widodo Rahardjo. 2012. Pengaruh Disiplin terhadap Prestasi Kerja Karyawan, Jurnal Ilmiah Merdeka Ekonomi, Vol.1 No.2 Maret, 165-174

Irfan, Moch. \& Arif R. P. 2014. Komunikasi Interpersonal Antar Guru dan Siswa serta Pengaruhnya terhadap Motivasi Belajar Siswa, Jurnal Ilmiah Manajemen Pendidikan Indonesia, Vol.1 No.1 September, 69-76

Khasanah, Hikmahtul, Setya Arum, D. Darmawan. 2010. Pengantar Manajemen Bisnis, Spektrum Nusa Press, Jakarta

Mahyanaila, Rahayu. 2016. Manajemen. Addar Press, Jakarta

Mardikaningsih, R. 2016. Variabel Kepemimpinan dan Lingkungan Kerja serta Pengaruhnya terhadap Kinerja Karyawan, Management \& Accounting Research Journal, Vol.1 No.1 November, 55-62

Mardikaningsih, R. et al. 2020. The Quality of Human Resources, Job Performance and Employee Loyalty, International Journal of Psychosocial Rehabilitation, Vol. 24 Issue 3, 2580-2592

Mathis, Robert L. \& John, H. Jackson. 2009. Human Resource Management. Edisi 10. Jakarta: Salemba Empat

Mondy, R. Wayne, 2010. Human Resource Management Eleventh Edition. New Jersey: Prentice Hall

Newstorm John W \& Davis, Keith. 1996. Perilaku dalam Organisasi. Erlangga: Jakarta

Oetomo, Hasan \& Didit D. 2004. Pengaruh Aspek Pendidikan, Pelatihan, Umur dan Pengalaman Kerja terhadap Perilaku Gaya Kepemimpinan, Jurnal Ekonomi-Manajemen, Vol.3 No.2 Desember, 11-22

Palembeta, Thoriq \& Samsul Arifin. 2014. Pengaruh Penilaian Kinerja terhadap Motivasi Kerja, Jurnal Ilmiah Manajemen Pendidikan Indonesia, Vol.1 No.1 September, 23-32

Pandji, Anoraga. 2005. Psikologi Kerja. Jakarta: Penerbit Rineka Cipta.

Putra, A. R., Eli Retnowati dan E. A. Sinambela. 2019. Pengaruh Komunikasi Kerja dan Integritas terhadap Kinerja Pegawai, Ebis, Jurnal Ekonomi Bisnis, Vol. 12 No. 1 Januari, 23-34

Putra, A. R., D. Darmawan, E. A. Sinambela. 2017. Pengawasan dan Koordinasi Kerja serta Pengaruhnya terhadap Produktivitas Kerja Karyawan, Akuntabilitas Jurnal Ilmiah Ilmu-ilmu Ekonomi, Vol.10, No.2, Desember 2017, 12-24 
Robbins, Stephen P. 2007. Organizational Behavior. New Jersey: Pearson Education Inc.

Samsul Arifin, D. Darmawan, Arif Rahman Putra. 2018. Teknik Komunikasi, Metromedia, Surabaya

Santosa, Aditya \& D. Darmawan. 2002. Hubungan Kepemimpinan, Budaya Organisasi dan Kinerja Karyawan, Jurnal Ilmu Manajemen, Vol 3 No 2, 81-92

Sinambela, E. A., Y. Rahman A. H., Mochamad I. 2019. Pengaruh Kedisiplinan dan Komunikasi Kerja terhadap Kinerja Karyawan, Relasi - Jurnal Ekonomi, Vol.15 No.2 Juli, 308-320

Sinambela, E. A., R. Mardikaningsih, S. Arifin, Halvinda D. A. 2020. Development of Self Competence and Supervision to Achieve Professionalism, Journal of Islamic Economics Perspectives, Vol. 1. No. 2, 33-42

Sjamsi, Nurul \& D. Darmawan. 2004. Peran Startegis Layanan pada Penyelenggaraan Pelayanan Publik, Jurnal Administrasi Publik, Vol.1 No.1 Desember, 83-95

Stonner, James, A.F. 1996. Manajemen. Prenhalindo; Jakarta

Toha, Miftah. 2004. Kepemimpinan Dalam Manajemen, Raja Grafindo Persada, Jakarta.

Werdati, Fauchil., Didit D. dan N. R. Solihah. 2020. The Role of Remuneration Contribution and Social Support in Organizational Life to Build Work Engagement, Journal of Islamic Economics Perspectives, Vol 1 No 2, 20-32

Winardi. 2002. Motivasi dan Permotivasian Dalam Manajemen, PT. Raja Grafindo Persada, Jakarta. 